\title{
Temporal assessment of the GPM satellite rainfall products across extremely arid regions
}

\author{
Mohammed Mahmoud ${ }^{1,2, ~ *, ~ S a f a ~}$ Mohammed $^{1}$, Mohamed Hamouda $^{1}$, and Mohamed Mohamed ${ }^{1}$ \\ ${ }^{1}$ Department of Civil and Environmental Engineering, United Arab Emirates University, Al Ain, Abu Dhabi, United Arab Emirates \\ ${ }^{2}$ Civil Engineering Department, University of Khartoum, Khartoum, Sudan
}

\begin{abstract}
Measuring rainfall precisely is always challenging due to its high variability, particularly in arid regions. Arid regions such as the Kingdom of Saudi Arabia (KSA) and the United Arab Emirates (UAE), suffer from rainfall scarcity and high variability of rainfall distribution. Thus, accurate monitoring and management of rainfall are one of the countries' priority to ensure proficient water resources management. This study validates the accuracy of the GPM IMERG rainfall products over the KSA and UAE to detect the large rainfall events over the period from 2015 to 2017 (two seasons). A temporal assessment was carried out to evaluate the performance of the GPM satellite to detect the rainfall events. The results showed that, for satellite detection, all of the three IMERG near real-time and post-real-time products had a significant detection accuracy. On the other hand, the error indicators showed that the final-run-product had a relatively low estimation error and bias compared with the other IMERG products. Overall, the results revealed that the IMERG final-run-product have the potential to serve as a consistent product to supplement ground measurements, particularly in regions with insufficient coverage by rain gauges. This study is considered one of the earliest evaluations of the GPM IMERG products in the region. Thus, the findings could be used to enhance the upcoming IMERG algorithms associated with the arid regions.
\end{abstract}

\section{Introduction}

Rainfall measurement is critical for water resources planning and management; as excess rainfall could cause floods which threatens life and property, whereas a smaller amount of rainfall could cause droughts that have detrimental effects on agricultural systems and can cause famines. Measuring rainfall precisely is always challenging due to the high variability of the rainfall. In addition, most water resources applications require accurate precipitation estimates to be developed, calibrated and validated [1].

Globally, there are three main techniques and instruments that can be used to measure precipitation; ground measurements (rain gauges), weather radar measurements, and satellite estimates [2]. Rain gauges provide a direct measurement of the precipitation and are considered as ground truth measurement. However, there are many errors associated with the rain gauge measurements, for instance, instrumental faults, false measurement of heavy rainfall, external factors such as weather condition [3]. In addition, rain gauges cannot represent the spatial variation of the rainfall. So, Multisatellite sensors have been introduced to tackle these problems and provide high spatiotemporal resolution measurements of rainfall [3, 4]. The Tropical Rainfall Measuring Mission (TRMM), was one of the popular weather satellites used to measure moderate to heavy rainfall. Many studies investigated the accuracy of this satellite such as $[5,6]$ and they recommended the use of TRMM to measure rainfall.

This study assesses the accuracy of a newly launched satellite called the Global Precipitation Measurement (GPM). The GPM satellite was launched on Feb 2014, through collaboration between National Aeronautics and Space Administration (NASA) and Japan Aerospace Exploration Agency (JAXA). NASA adopted the Integrated Multi satellitE Retrievals for GPM (IMERG) algorithm to process high-resolution precipitation estimates. IMERG provides near-real-time products (Early and Late-run) and post-real-rime product (final-run). IMERG near-real-time products could allow researchers to build many hydrological applications such as flood forecasting, early warning systems, and others to help protect lives and property. Consequently, it is always significant to validate such products[4, 7].

The Kingdom of Saudi Arabia (KSA) and the United Arab Emirates (UAE) located in an arid region that suffers from rainfall scarcity and high variability of rainfall distribution. Thus, accurate monitoring and management of the rainfall are one of the countries' priorities to ensure proficient water resources management. A better understanding of the rainfall pattern in a country with a high variation of the rainfall is always challenging. Thus, several measurement techniques should be used to sustain high-resolution measurements.

This study aims to investigate the accuracy of GPM IMERG rainfall products over KSA and UAE by 
performing a temporal assessment using the rainfall events occurred during the period from 2015 to 2017. The assessment will reveal the differences between the rainfall measurements of the gauge data and the precipitation estimated by the satellite. Moreover, the assessment will evaluate the performance of the three IMERG products (post and near real-time products).

\section{Study area}

This study focuses on two countries; the Kingdom of Saudi Arabia, and United Arab Emirates (UAE) due to the availability of the data. KSA located between $43^{\circ}-55^{\circ} \mathrm{E}$ and $32^{\circ}-16^{\circ} \mathrm{N}$, which is located in the South-eastern part of the Arabian Peninsula, between $51^{\circ} \mathrm{E}-56^{\circ} \mathrm{E}$ and $22^{\circ} \mathrm{N}-26^{\circ} \mathrm{N}$ (Fig. 1). Similar to other Arabian Gulf countries, the two countries suffer from scarce rainfall and hot climate, which increases the evaporation rate. In addition, both countries have high variation in the distribution of the rainfall due to the variation in its topography. The KSA and UAE are classified as a tropical and subtropical desert region $[4,8]$, where temperatures reach an average of $50 \mathrm{C}^{\circ}$ in July and August [9]. The precipitation over KSA has high variability, with an estimation of around $100 \mathrm{~mm}$ total annual rainfall [10, 11]. While according to the annual report provided by the National Centre of Metrology (NCM), the average annual rainfall is $45 \mathrm{~mm}$ [9]. Overall, some studies concluded that in the $\mathrm{KSA}$ and $\mathrm{UAE}$, the average annual rainfall significantly decreased in the past 20 years [11-13].

\section{Methodology}

Several steps were carried out to evaluate the accuracy of the IMERG precipitation products. The rain-gauge data and IMERG data were collected, processed and formulated.

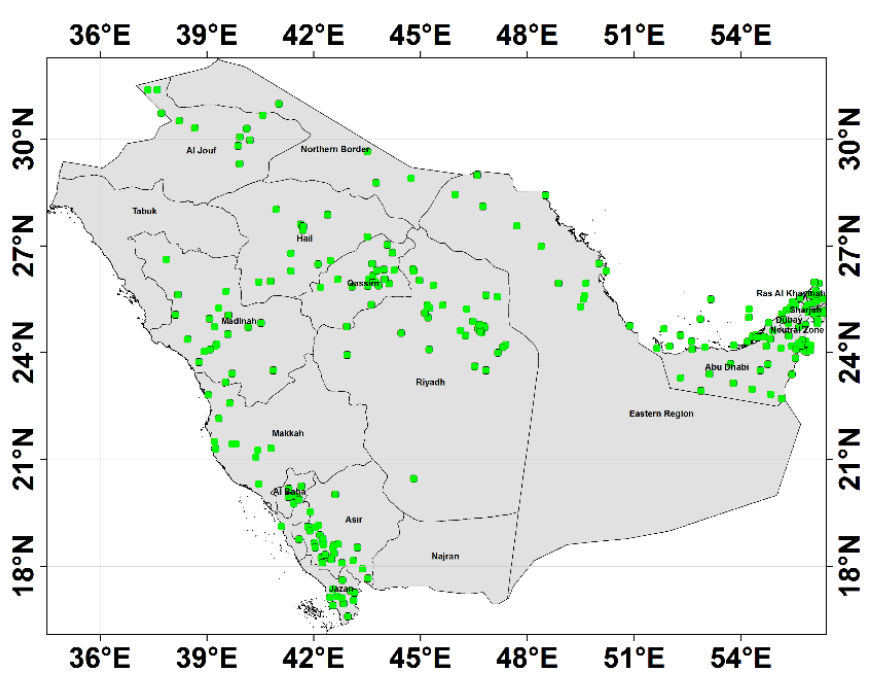

Fig. 1. Study area and distribution of the rain gauge network over the KSA and UAE.

\subsection{Rain gauge and satellite datasets}

Daily rainfall measurements were obtained for the period 2015 to 2017 from the rain gauge stations, that operated by the metrological authorities of both countries (KSA and UAE). The coordinates of each rain gauge station were obtained and converted to the UTM system. It can be observed from Fig.1, that Riyadh region and Abu Dhabi emirate has the majority of these stations. The rainfall data collected over KSA accounted for 5200 rain observations were recorded by 189 stations. While UAE rain gauge stations included 1600 rain records.

In this study, the GPM level-3 was used as recommended for research purpose by NASA. This product resulted from using Integrated Multi-satellitE Retrievals for GPM (IMERG) algorithm, which combines the microwave (MW), and the infrared (IR) techniques [14, 15]. The IMERG algorithm provides precipitation estimates with high spatiotemporal resolution (approximately $11 \times 11 \mathrm{Km}$ every 30 minutes). IMERG delivers three main products; near-real-time products (Early-run-product and Late-run-product) and post-realtime product (Final-run-product). The IMERG products were downloaded from the NASA Precipitation Processing System (PPS) https://pmm.nasa.gov/dataaccess/downloads/gpm.

\subsection{Data analysis}

Rain gauge data was stored in a database format using MS Access and connected to a script code that merges rain records of different stations reported on the same day. Thus, the script could identify the large rainfall events that had wider coverage. The processed IMERG files were analyzed to ensure the files cover the entire KSA and UAE. The extent of the satellite rainfall estimates was determined through developing event maps using ArcGIS software. The maps helped in revealing the differences between the three IMERG products.

The subsequent step is to conduct a point-to-point assessment. This would be possible by finding the nearest GPM intersection to the rain gauge coordinates. This step starts by selecting the correct processed IMERG file, by identifying the event date and station coordinate. Then, searching for the nearest satellite coordinate existing within $11 \mathrm{x} 11 \mathrm{Km}^{2}$ from the station coordinate. Finally, the module extracts the satellite rain estimates from the file and compare them with ground measurements.

The final step is evaluating the detection accuracy of the Satellite products. In this study, a temporal assessment was carried out to evaluate the performance of the GPM satellite in detecting the large rainfall events that occurred during the study period, (Jan 2015 to Dec 2017).

\subsection{Statistical performance measures}

Five statistical performance measures were used to assess the performance of GPM IMERG products. Many studies categorized these performance measures into three groups based on their use $[4,7,16,17]$. The contingency of the satellite estimates was assessed using the probability of 
detection (POD) as shown in Eq. (1). The errors associated with the satellite estimates were evaluated using the mean absolute error (MAE), root mean squared error (RMSE), and relative bias (RB) using Eqs (2) - (4) respectively. The agreement between the satellite estimates and the rain gauge data were checked through the correlation coefficient (CC) using Eq. (5).

$$
\begin{array}{lc}
\text { POD } & \frac{P_{S G}}{P_{S G}+P_{G}} \\
\text { MAE } & \frac{1}{n} \sum_{i=1}^{n}\left|X_{i}-Y_{i}\right| \\
\text { RMSE } & \sqrt{\frac{1}{n} \sum_{i=1}^{n}\left(X_{i}-Y_{i}\right)^{2}} \\
\text { RB } & \frac{1}{n} \sum_{i=1}^{n}\left(X_{i}-Y_{i}\right) \\
\sum_{i=1}^{n} Y_{i} & x 100 \% \\
\text { CC } & \frac{1}{n} \sum_{i=1}^{n}\left(X_{i}-\bar{X}\right)\left(Y_{i}-\bar{Y}\right) \\
& \sigma_{x} \sigma_{y}
\end{array}
$$

\section{Results and discussion}

The following subsections will demonstrate the temporal assessment results, which were obtained by using the statistical performance measures. Generally, the evaluation was intended to assess the contingency of satellite estimates, bias and error of satellite precipitation products, and consistency between rain-gauge data and satellite estimates.

\subsection{Evaluation of the Satellite detection}

The probability of detection (POD) was used to evaluate the capability of the GPM satellite to detect rainfall. Overall, it can be observed that the events occurring in 2017 had higher detection accuracy than those in 2016 and 2015 (Table 1, 2). This could due to several reasons; for instance, the meteorological authorities in both countries used new instruments to measure the rainfall in 2017 and thus they were more accurate than the ones used in the previous two years. Another interpretation is that the algorithm used by NASA was significantly improved throughout the years, so the satellite estimates could have improved accordingly. Over the UAE, the early-runproduct showed POD ranges of 0.49 to $1,0.76-1,0.81-1$ for 2015, 2016 and 2017 respectively. These results remain approximately the same for the late-run-product. However, the final-run-product revealed significant improvement for all large events occurring during the study period with an average of 0.88 to 1 POD and CSI. In KSA, the POD values were very high compared with UAE values for the same period. Overall, the final-run-product performed well in detecting rainfall during large storm events than the other two IMERG products. This finding was supported by

\begin{tabular}{|c|c|c|c|c|}
\hline \multicolumn{2}{|c|}{ Event Date } & \multicolumn{3}{|c|}{ IMERG Product } \\
\hline & & Early-run & Late-run & Final-Run \\
\hline \multirow{5}{*}{$\frac{n}{\bar{d}}$} & 17-Nov & 0.95 & 0.95 & 0.95 \\
\hline & 23-Nov & 0.9 & 0.93 & 0.93 \\
\hline & 24-Nov & 0.95 & 0.96 & 0.96 \\
\hline & 23-Dec & 0.77 & 0.86 & 0.86 \\
\hline & 30-Dec & 0.93 & 0.96 & 0.96 \\
\hline \multirow{5}{*}{$\frac{0}{\sqrt{0}}$} & 4-Apr & 0.92 & 1 & 1 \\
\hline & 12-Apr & 0.97 & 0.99 & 0.99 \\
\hline & 29-Apr & 1 & 1 & 1 \\
\hline & 27-Nov & 0.98 & 0.96 & 0.96 \\
\hline & 28-Nov & 0.98 & 0.98 & 0.98 \\
\hline \multirow{3}{*}{$\overline{\bar{\delta}}$} & 14-Feb & 0.9 & 0.93 & 0.93 \\
\hline & 13-May & 0.97 & 0.97 & 0.97 \\
\hline & 21-Nov & 0.88 & 0.88 & 0.88 \\
\hline
\end{tabular}
many studies that investigated the accuracy of the IMERG products such as [4] in Saudi Arabia; [18] in Pakistan.
Table 1. POD values for UAE events

\begin{tabular}{ccccc}
\hline \multicolumn{2}{l}{ Event Date } & \multicolumn{3}{c}{ IMERG Product } \\
& & Early-run & Late-run & Final-Run \\
\hline \multirow{2}{*}{ 19-Jan } & 0.98 & 0.98 & 1 \\
& 20-Jan & 0.49 & 0.49 & 0.51 \\
& 26-Dec & 1 & 0.97 & 1 \\
\cline { 2 - 5 } & 3-Jan & 1 & 1 & 1 \\
13-Jan & 0.76 & 0.82 & 1 \\
& 7-Mar & 0.98 & 0.98 & 0.95 \\
& 8-Mar & 1 & 1 & 1 \\
& 9-Mar & 0.99 & 0.99 & 0.99 \\
& 22-Mar & 0.97 & 0.98 & 0.98 \\
\cline { 2 - 5 } & 18-Feb & 0.81 & 0.86 & 0.98 \\
& 26-Feb & 1 & 1 & 1 \\
& 24-Mar & 0.98 & 1 & 1 \\
& 25-Mar & 1 & 1 & 1 \\
& 26-Mar & 1 & 1 & 1 \\
\hline
\end{tabular}

Table 2. POD values for KSA events

\subsection{Consistency of Satellite estimates}

The correlation coefficient (CC) was used to check the consistency between the satellite estimates and the ground measurements. Generally, for the UAE the results revealed that the early-run-product is more correlated with the ground observations than the late and final-run-products (Table 3). The large events showed a high CC for the earlyrun-product (average of 0.036-0.737); while the late and the final-run-product showed low correlation ranges on the average between $0.005-0.642$ and 0.005 to 0.605 respectively. It is surprising to observe that the near-realtime products (Early and late-run-product) to have a higher 
correlation with ground measurements than the calibrated post-real-time product (final-run-product). Few studies shared the same findings as [19] in Malaysia. Conversely, many other researchers concluded the final-run-product had a higher correlation than the other products such as $[4$, $18]$.

On the other hand, KSA results showed that the finalrun-product had the highest correlation values than the other near-real-time products. This result can be interpreted with the calibration wish was performed to produce the product. These findings were supported by many researchers in the field such as $[1,4]$.

Table 3. Consistency of satellite estimates over UAE

\begin{tabular}{clccc}
\hline \multicolumn{2}{c}{ Event Date } & \multicolumn{3}{c}{ IMERG Product } \\
& & Early-run & Late-run & Final-Run \\
\hline \multirow{2}{*}{ 19-Jan } & 0.036 & 0.041 & 0.003 \\
& 20-Jan & 0.737 & 0.371 & 0.343 \\
& 26-Dec & 0.092 & 0.027 & 0.155 \\
\cline { 2 - 5 } & 3-Jan & 0.648 & 0.642 & 0.605 \\
(3-Jan & 0.06 & 0.049 & 0.063 \\
& 7-Mar & 0.197 & 0.295 & 0.287 \\
& 8-Mar & 0.199 & 0.005 & 0.411 \\
& 9-Mar & 0.333 & 0.27 & 0.286 \\
& 22-Mar & 0.034 & 0.07 & 0.194 \\
\cline { 2 - 5 } & 18-Feb & 0.195 & 0.305 & 0.084 \\
& 26-Feb & 0.351 & 0.363 & 0.03 \\
\hline \multirow{2}{*}{} & 24-Mar & 0.091 & 0.112 & 0.005 \\
& 25-Mar & 0.492 & 0.567 & 0.442 \\
& 26-Mar & 0.035 & 0.038 & 0.012 \\
\hline
\end{tabular}

Table 4. Consistency of satellite estimates over KSA

\begin{tabular}{|c|c|c|c|c|}
\hline \multicolumn{2}{|c|}{ Event Date } & \multicolumn{3}{|c|}{ IMERG Product } \\
\hline & & Early-run & Late-run & Final-Run \\
\hline \multirow{5}{*}{ 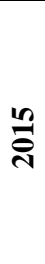 } & 17-Nov & 0.357 & 0.451 & 0.384 \\
\hline & 23-Nov & 0.338 & 0.352 & 0.378 \\
\hline & 24-Nov & 0.336 & 0.378 & 0.384 \\
\hline & 23-Dec & 0.191 & 0.204 & 0.181 \\
\hline & 30-Dec & 0.488 & 0.492 & 0.462 \\
\hline \multirow{5}{*}{$\stackrel{0}{\bar{\sim}}$} & 4-Apr & 0.501 & 0.465 & 0.511 \\
\hline & 12-Apr & 0.281 & 0.321 & 0.309 \\
\hline & 29-Apr & 0.1 & 0.031 & 0.169 \\
\hline & 27-Nov & 0.58 & 0.651 & 0.625 \\
\hline & 28-Nov & 0.182 & 0.241 & 0.371 \\
\hline \multirow{3}{*}{ 곡 } & 14-Feb & 0.258 & 0.468 & 0.603 \\
\hline & 13-May & 0.035 & 0.084 & 0.268 \\
\hline & 21-Nov & 0.579 & 0.702 & 0.756 \\
\hline
\end{tabular}

\subsection{Satellite Error evaluation}

Three statistical performance measures - MAE, RMSE, and BIAS - were used to assess the error associated with the satellite rainfall estimates. Overall, the final-runproduct had the lowest estimation error among the other products (Table 5, and 6). The UAE results showed that over the period from 2015 to 2017 the MAE and RMSE for early-run-product ranged from 3.22 to $40.11 \mathrm{~mm}$ and 4.36 to $53.84 \mathrm{~mm}$ respectively. These error values were considered very high compared with other studies in the region [4]. The errors remain without noticeable enhancement when using the late-run-product. However, the final-run-product showed a considerable improvement in the estimation error with approximately $11 \%$ reduction for both MAE and RMSE. In terms of BIAS results, again the final-run-product had very low bias compared with the other IMERG products. The early and late-run products revealed an overestimation of the rainfall with an average of $1.1 \%$. In contrast, the BIAS estimator showed the finalrun-product bias to be $0.4 \%$ on average. On the other hand, KSA showed a similar trend for the error and the bias values. As for MAE and RMSE, the values range from $3.85-19.88 \mathrm{~mm}$, and 5.64 to $37 \mathrm{~mm}$ respectively for the early-run-product. The values enhanced for the final-runproduct to range from $3-17 \mathrm{~mm}$ and 5 to $29 \mathrm{~mm}$. Overall, it can be concluded that for the error and bias of the finalrun-product was performed better than the other near-realtime products in both countries. This finding was indicated by previous studies investigating the IMERG products around the globe $[4,17]$

\section{Conclusion}

This article intended to evaluate the performance of the GPM satellite on detecting major rainfall events on two extremely arid regions: KSA and UAE. Three IMERG products were investigated through a temporal assessment over the period 2015 to 2017. Six performance measures were used to analyse the consistency of the satellite estimates with rain gauge data, the bias and the error associated with the satellite estimates and the detection accuracy of the satellite. The outcomes of this research can be summarized as follows:

1. Almost all the IMERG products exhibited relatively high precipitation detection, specifically for the events that occurred in 2017. The late-run-product showed better performance than the early-run-product. While the final-run-product showed a significant improvement in the detection accuracy which exceeded the near-real-time products.

2. In the UAE, the IMERG early-run-product estimates had a considerable $\mathrm{CC}$ than the other two products (late and final run-products). However, the differences in the $\mathrm{CC}$ ranges was not significant between the IMERG products. The high correlation of the early-run-product could be reliable input data that could help in creating floods early warning systems and other hydrological applications. In contrast, the KSA results revealed that the final-run-product showed a remarkable 
performance in terms of consistency that the other

IMERG products.

Table 5. Error estimation for IMERG products over UAE

\begin{tabular}{|c|c|c|c|c|c|c|c|c|c|c|}
\hline \multirow{2}{*}{\multicolumn{2}{|c|}{$\begin{array}{l}\text { IMERG Product } \\
\text { Event Date }\end{array}$}} & \multicolumn{3}{|c|}{ Early } & \multicolumn{3}{|c|}{ Late } & \multicolumn{3}{|c|}{ Final } \\
\hline & & MAE & RMSE & BIAS & MAE & RMSE & BIAS & MAE & RMSE & BIAS \\
\hline \multirow{3}{*}{$\frac{n}{2}$} & 19-Jan & 13.27 & 18.49 & 0.16 & 12.94 & 17.91 & 0.32 & 10.29 & 13.68 & -0.29 \\
\hline & 20-Jan & 5.14 & 6.87 & -2.5 & 5.29 & 6.83 & -2.3 & 4.77 & 6.6 & -2.12 \\
\hline & 26-Dec & 4.46 & 8.38 & 0.62 & 4.73 & 8.93 & 0.79 & 13.13 & 22.94 & 6.3 \\
\hline \multirow{6}{*}{$\stackrel{0}{\circ}$} & 3-Jan & 5.03 & 6.96 & 0.18 & 5.47 & 7.03 & 0.47 & 7.57 & 9.15 & 1.44 \\
\hline & 13-Jan & 3.22 & 4.36 & -1.75 & 3.09 & 4.13 & -1.63 & 2.9 & 3.97 & -1.28 \\
\hline & 7-Mar & 11.22 & 15.52 & 5.22 & 8.96 & 12.54 & 3.44 & 6.21 & 8.01 & 1.84 \\
\hline & 8-Mar & 28.65 & 39.45 & 2.36 & 28.93 & 42.05 & 2.32 & 12.94 & 19.36 & -0.74 \\
\hline & 9-Mar & 40.11 & 53.84 & 0.97 & 48.36 & 63.32 & 1.46 & 24.32 & 44.22 & -0.68 \\
\hline & 22-Mar & 6 & 7.69 & 1.88 & 4.49 & 5.53 & 1.19 & 4 & 4.79 & 1.13 \\
\hline \multirow{5}{*}{ స } & $18-\mathrm{Feb}$ & 7.69 & 12.12 & 0.63 & 7.36 & 10.8 & 0.53 & 4.87 & 7.42 & -1.51 \\
\hline & $26-\mathrm{Feb}$ & 7.78 & 12.12 & 0.39 & 9.75 & 14.35 & 0.87 & 7.02 & 10.45 & -0.39 \\
\hline & 24-Mar & 25.03 & 31.16 & 1.27 & 25.15 & 33.51 & 1.1 & 14.03 & 20.37 & 0 \\
\hline & 25-Mar & 31.17 & 46.95 & 4.66 & 35.18 & 50.97 & 5.39 & 17.59 & 23.72 & 2.28 \\
\hline & 26-Mar & 9.52 & 15.08 & 0.38 & 10.92 & 19.14 & 1.51 & 8.5 & 14.25 & -0.17 \\
\hline
\end{tabular}

Table 6. Error estimation for IMERG products using MAE, RMSE, and BIAS

\begin{tabular}{|c|c|c|c|c|c|c|c|c|c|c|}
\hline \multirow{2}{*}{\multicolumn{2}{|c|}{$\begin{array}{l}\text { IMERG Product } \\
\text { Event Date }\end{array}$}} & \multicolumn{3}{|c|}{ Early } & \multicolumn{3}{|c|}{ Late } & \multicolumn{3}{|c|}{ Final } \\
\hline & & MAE & RMSE & BIAS & MAE & RMSE & BIAS & MAE & RMSE & BIAS \\
\hline \multirow{5}{*}{$\frac{n}{2}$} & 17-Nov & 13.4 & 22.94 & 3.45 & 11.96 & 20.38 & 3.2 & 6.83 & 9.92 & 1.2 \\
\hline & 23-Nov & 7.25 & 10.6 & -0.08 & 7.15 & 10.46 & 0.02 & 7.45 & 10.53 & 0.14 \\
\hline & 24-Nov & 14.76 & 21.62 & -0.46 & 13.93 & 20.93 & -0.26 & 13.91 & 20.74 & -0.12 \\
\hline & 23-Dec & 6.05 & 10.17 & -1.14 & 5.8 & 9.92 & -1.03 & 6.18 & 10.22 & -1.13 \\
\hline & 30-Dec & 3.85 & 5.64 & 0.14 & 3.67 & 5.18 & 0.18 & 3.46 & 5.66 & 0.14 \\
\hline \multirow{5}{*}{$\frac{0}{\circ}$} & 4-Apr & 9.57 & 14.54 & -0.22 & 9.8 & 15.63 & -0.08 & 8.71 & 14.29 & -0.95 \\
\hline & 12-Apr & 8.87 & 13.15 & 0.47 & 10.2 & 14.1 & 0.74 & 6.42 & 11.05 & -0.23 \\
\hline & 29-Apr & 10.76 & 15.19 & 0.58 & 9.67 & 13.52 & 0.56 & 7.1 & 10.85 & -0.39 \\
\hline & 27-Nov & 12.13 & 18.71 & 0.48 & 11.43 & 16.97 & 0.56 & 10.58 & 15.2 & 0.22 \\
\hline & 28-Nov & 16.31 & 27.22 & 1.28 & 16.49 & 27.58 & 1.52 & 8.88 & 11.37 & 0.25 \\
\hline \multirow{3}{*}{$\stackrel{\sqrt{\sigma}}{\bar{c}}$} & 14-Feb & 19.88 & 37.05 & -1.82 & 18.49 & 34.41 & -1.65 & 17.15 & 29.52 & -1.23 \\
\hline & 13-May & 15.93 & 23.44 & 1.79 & 14.33 & 21.06 & 1.46 & 8.76 & 12.28 & -0.15 \\
\hline & 21-Nov & 14.01 & 20.77 & -0.74 & 12.45 & 18.65 & -0.89 & 12.89 & 21.63 & -1.73 \\
\hline
\end{tabular}

3. In terms of error, the final-run-product had the lowest error and bias among the other products.

To conclude, the results suggested that the GPM rainfall products had some deficiencies in rainfall estimation over the arid regions. The poor performance of the satellite could be resulting from the high variation of the rainfall characteristics due to the variation in the geographical features of the KSA and the UAE. Thus, further investigation of the GPM performance is required in arid and semiarid regions. Overall, the final-run-product showed promising results, which can be used to complement, and perhaps substitute ground data for regions with insufficient coverage by rain gauges.

The authors would like to thank the support provided by the College of Graduate Studies at UAEU for funding this research. 
1. Sharifi, E.; Steinacker, R.; Saghafian, B. Multi timescale evaluation of high-resolution satellite-based precipitation products over northeast of Austria. Atmos. Res. 2018, 206, 46-63, doi:10.1016/j.atmosres.2018.02.020.

2. Li, Z.; Yang, D.; Hong, Y. Multi-scale evaluation of high-resolution multi-sensor blended global precipitation products over the Yangtze River. $J$. Hydrol. 2013, 500, 157-169, doi:10.1016/j.jhydrol.2013.07.023.

3. Tapiador, F. J.; Turk, F. J.; Petersen, W.; Hou, A. Y.; García-Ortega, E.; Machado, L. A. T.; Angelis, C. F.; Salio, P.; Kidd, C.; Huffman, G. J.; de Castro, M. Global precipitation measurement: Methods, datasets and applications. Atmos. Res. 2012, 104-105, 70-97, doi:10.1016/j.atmosres.2011.10.021.

4. Mahmoud, M. T.; Al-Zahrani, M. A.; Sharif, H. O. Assessment of global precipitation measurement satellite products over Saudi Arabia. J. Hydrol. 2018, 559, 1-12, doi:10.1016/j.jhydrol.2018.02.015.

5. Li, M.; Shao, Q. An improved statistical approach to merge satellite rainfall estimates and raingauge data. J. Hydrol. 2010, 385, 51-64, doi:10.1016/j.jhydrol.2010.01.023.

6. Prakash, S.; Mitra, A. K.; Aghakouchak, A.; Liu, Z.; Norouzi, H.; Pai, D. S. A preliminary assessment of GPM-based multi-satellite precipitation estimates over a monsoon dominated region. J. Hydrol. 2016, 1-12, doi:10.1016/j.jhydrol.2016.01.029.

7. Tang, G.; Ma, Y.; Long, D.; Zhong, L.; Hong, Y. Evaluation of GPM Day-1 IMERG and TMPA Version-7 legacy products over Mainland China at multiple spatiotemporal scales. J. Hydrol. 2016, 533, 152-167, doi:10.1016/j.jhydrol.2015.12.008.

8. Kumar, K. N.; Ouarda, T. B. M. J. Precipitation variability over UAE and global SST teleconnections. J. Geophys. Res. Atmos. 2014, 1-10, doi:10.1002/2014JD021724.Received.

9. National Centre of Meteorology Climate Yearly Report 2003-2017 Available online: http://www.ncm.ae/climate-reportsyearly.html?id=26 (accessed on Jan 6, 2018).

10. Horton, R.; Gornitz, V.; Bowman, M.; Blake, R. Climate observations and projections. Ann. N. Y. Acad. Sci. 2010, 1196, 41-62, doi:10.1111/j.17496632.2009.05314.x.
11. Hasanean, H.; Almazroui, M. Rainfall: Features and Variations over Saudi Arabia, A Review. Climate 2015, 3, 578-626, doi:10.3390/cli3030578.

12. Murad, A. A. An Overview of Conventional and Non-Conventional Water Resources in Arid Region: Assessment and Constrains of the United Arab Emirates (UAE). J. Water Resour. Prot. 2010, 02, 181-190, doi:10.4236/jwarp.2010.22020.

13. Ouarda, T. B. M. J.; Charron, C.; Niranjan Kumar, K.; Marpu, P. R.; Ghedira, H.; Molini, A.; Khayal, I. Evolution of the rainfall regime in the united arab emirates. J. Hydrol. 2014, 514, 258-270, doi:10.1016/j.jhydrol.2014.04.032.

14. Huffman, G. J.; Bolvin, D. T.; Braithwaite, D.; Hsu, K.; Joyce, R.; Kidd, C.; Nelkin, E. J.; Xie, P. NASA Global Precipitation Measurement (GPM) Integrated Multi-satellitE Retrievals for GPM (IMERG). 2015, 26.

15. NASA Global Precipitation Measurement (GPM) Mission Overview | Precipitation Measurement Missions Available online: http://pmm.nasa.gov/GPM (accessed on Feb 20, 2016).

16. Ning, S.; Wang, J.; Jin, J.; Ishidaira, H. Assessment of the Three Latest GPM-era High Resolution Satellite Precipitation Products against Gauged Data over the Chinese Mainland : Initial Results. 2016, 116.

17. Mahmoud, M. T.; Hamouda, M. A.; Mohamed, M. M. Spatiotemporal evaluation of the GPM satellite precipitation products over the United Arab Emirates. Atmos. Res. 2019, 219, 200-212, doi:10.1016/j.atmosres.2018.12.029.

18. Anjum, M. N.; Ding, Y.; Shangguan, D.; Ahmad, I.; Ijaz, M. W.; Farid, H. U.; Yagoub, Y. E.; Zaman, M.; Adnan, M. Performance evaluation of latest integrated multi-satellite retrievals for Global Precipitation Measurement (IMERG) over the northern highlands of Pakistan. Atmos. Res. 2018, 205, 134-146, doi:10.1016/j.atmosres.2018.02.010.

19. Tan, M. L.; Santo, H. Comparison of GPM IMERG, TMPA 3B42 and PERSIANN-CDR satellite precipitation products over Malaysia. Atmos. Res. 2018, 202, 63-76, doi:10.1016/j.atmosres.2017.11.006. 